\title{
Roles of different packaging materials on the quality and shelf life of yogurt
}

\author{
Soma Fatah RASUL ${ }^{1 *}$ (D), Rabar Jalal NOORI ${ }^{1}$, Kale Mohammed ALI ${ }^{1}$, Rezhna Baiz KHDHIR ${ }^{1}$, \\ Shakar Rasul AHMED ${ }^{1}$, Ako Majeed QADIR ${ }^{1}$
}

\begin{abstract}
The main functions of food packaging are providing an essential protection from the environment and from chemical and physical challenges. This study evaluated the effect of different packaging material on the chemical, microbiological and sensory characteristics of yogurt during 14 days of storage. To investigate the potential impact of packaging on yogurt quality, five different types of packaging material used including Glass(A), Aluminum(B), non-identified plastic (C), Polypropylene plastic (PP) (D) and mud(E). The tested materials selected based on the highly uses for local yogurt packaging in Kurdistan region. Analyses of samples were carried out at 1st, 7 th and 14th days of storage with in the same yogurt process and storage condition. For chemical tests ( $\mathrm{pH}$, titratable acidity and dry matter percentage) determined. In all cases, $\mathrm{pH}$ values significantly decreased over storage time (ranged from 4.6 to 4.2 ), whereas titratable acidity (ranged from $0.40 \%$ to $1.11 \%$ ) and dry matter content gradually increased (ranged from $82.30 \%$ to $98 \%$ ). To investigate the microbiological quality of yogurt samples, total viable count was obtained by inoculating the sample on nutrient agar (NA) and potato Dextrose Agar (PDA). During storage the number of isolates obtained varies from one yogurt sample to the other. After 14th days of storage Sample B has the highest bacteria and fungi count at 106 dilutions. For sensory evaluation a total of 12 members (six male and six female) participated and performed sensory analysis during 14 days storage. The result indicated that the yogurt samples did not show any significant difference among sensory properties in the 1st session. The scores of yogurt sample in aluminum container were slightly higher than others in most of the sensory properties in day 14th of storage.
\end{abstract}

Keywords: yogurt; packaging material; food quality.

Practical Application: Chemical, microbiological analyses and sensory characteristics of yogurt.

\section{Introduction}

Packaging materials is one of the main factors that food quality and safety depends on. It is used to protect food against microbiological, chemical and physical contamination. A wide range of packaging materials are used for food products. However, some of these materials that are used for food packaging can react with the content and cause alterations in the product. In general, food packaging materials various with respect to relatively short shelf life and safety aspects (Mohanty \& Swain, 2017). Plastic, glass, metal and paper were identified as the most common types of food packaging materials (Brody, 2006; Geueke et al., 2018). Since mid-twentieth, the most used type of food packaging is plastic because of their low cost, processibility, good aesthetic quality, and excellent physiochemical properties (Mohanty \& Swain, 2017). Normally plastic packaging consists of single polymers, e.g., polyethylene terephthalate (PET), polypropylene (PP), density polyethylene (DPE), polystyrene (PS), and polyvinylchloride (PVC) (Geueke et al., 2018). Glass also has an extremely long history in food packaging as it maintains product freshness for a long period of time without impairing taste or flavor (Marsh \& Bugusu, 2007). Aluminum and steel are one of the most predominantly used in food packaging. Specifically, aluminum provides a highly effective barrier to the effects of air, temperature, moisture, and chemical attack (Marsh \& Bugusu, 2007). However, all these types of material, it has a serious drawback when they are not built in a standard approach depending on food products. Recycling of these materials and using them in food packaging increases the possibility sources of contamination. Metal and glass, are generally considered suitable for food packaging in terms of quality and safety, because their chemical and physical properties do not change over time and the heat required for remelting destroys microorganisms and organic compounds (Marsh \& Bugusu, 2007). However, for some packaging materials such as aluminum, steel, and glass double recycling may lead to the accumulation of unwanted metal ions in the material (Geueke et al., 2018). Aluminum Recycling and reusing them in food packaging increases the possibility sources of contamination.

In comparison with the developed countries, in Iraq; food safety is not considered as a public health issue. Today plastic and aluminum materials are widely used for foods packing across Iraqi-Kurdistan Region. Various plastic items available in the local market that have not identified, specifically in local dairy products. 
Despite the availability of numerous types of commercial dairy products in Iraq, local soft white cheese and yogurt are still very popular among people (Alhelfi, 2016).

Yogurt is one of the oldest fermentation products known to humans with high consumption worldwide especially in the Middle East where it plays a significant role in the family diet. Mainly because it has a positive impact on the human health. The presence of calcium, phosphorus, potassium, vitamins A, B2 and B12, high biological value proteins and essential fatty acids are among the beneficial effects that the consumption of yogurt provides (Hadjimbei et al., 2020). Due to chemical composition of this matrix and the health image related to milk, yogurt have been considered as the most successful carrier of probiotics (Pena et al., 2021). As a fermented product it is usually obtained by lactic acid fermentation using diverse bacterial cultures. In most of the fermented product's some species of Lactobacillus, genera of Lacto-coccus, Streptococcus are commonly used as a starter culture (Pena et al., 2021). Recently, many research has been carried out to understand and improve the texture, taste, and the health properties of yogurt. (Hadjimbei et al., 2020) and (El-Shafei et al. 2019) studied Goats'milk yogurts fortified with a plant extract (Pistacia atlantica resin extracts, quinoa extracts) and probiotic microorganisms (Saccharomyces boulardii) in order to combine the beneficial effects and enhanced the quality of final product. Results proved that Pistacia extracts improved the viability of lactic acid bacteria with retention of functional fatty acids as well aa supplementation of goats' milk with quinoa extracts increased the apparent viscosity and changed the yoghurt protein matrix. Dairy foods have been presented as the most successful carrier of probiotics due to chemical composi-tion of this matrix and the health image related to milk. Dairy foods have been presented as the most successful carrier of probiotics due to chemical composition of this matrix and the health image related to milk.

Yogurt announced as a perishable food product because of the complex composition of its matrix and the susceptibility to microbial contamination (Germani et al., 2014). Regarding undesirable microorganisms, foodborne disease from consumption of dairy products have been mainly implicated with Campylobacter jejuni, Escherichia coli, Listeria monocytogenes, and Salmonella entertica (Pal et al., 2016). Staphylococcus aureus also are common foodborne pathogens and the presence of it in yogurt could be due to poor hygienic processing, handling and packaging (Prescott et al., 2004). In addition, according to (Carvalho et al., 2021) S. aureus can form biofilms in low density polyethylene packaging in Minas Frescal cheese whey, when stored at $5{ }^{\circ} \mathrm{C}$.

As a result, the right selection of packaging materials maintains quality characteristics of food products such as physicochemical and microbiological parameters during the storage and distribution. To investigate the potential impact of packaging on yogurt quality during storage, the chemical, microbiological and sensory characteristics of yogurt measured.

\section{Material and method}

\subsection{Yogurt production and packaging selection}

The milk used for yogurt production obtained from a local village within the $\mathrm{pH}$ range, about 6.8 . Yogurt preparation followed by general processing steps which includes pasteurizing the milk at low temperature, and cooling it down to $42^{\circ} \mathrm{C}$. Then the starter culture added to ferment the milk which is containing Lactobacillus bulgaricus and Streptococcus thermophilus. After adding the culture, the yogurts were immediately conditioned into five types of packaging: Glass (A), Aluminum (B), nonidentified plastic (C), polypropylene plastic (D) and Mud (E) (Figure 1). To reduce the error percentage two samples in each container provided. After packaging, samples held at warm temperature for about three to four hours while the incubation process takes place. Sample testing was carried out on the 1st, 7th and 14th days of storage under the same storage condition.

\subsection{Chemical and microbiological analyses}

For chemical tests, the yogurt's $\mathrm{pH}$ was measured by the $\mathrm{pH}$ meter (HI $2211 \mathrm{pH}$ and ORP Benchtop Meter). Each measurement was carried out at the same date as a sensory analysis session (1st, 7 th and 14th days of storage). Titirable acidity percentage (lactic acid \%) dry matter percentage of the yogurt products obtained according to (Bradley et al., 1992), (Association of Official Analytical Chemists, 2000). For that purpose, yogurt samples were placed in an oven at $105^{\circ} \mathrm{C}$ for $3 \mathrm{hrs}$.

Nutrient agar and potato Dextrose Agar (PDA) as a general-purpose medium for microbes used for detecting the microorganisms. Growth of organism on selected media examined under microscopic to identify the organism's colonies morphology.

\subsection{Sensory evaluation}

The Sensory quality for yogurt is a function of many factors which influences the consumer's acceptation (Kliks et al., 2019; Harper et al., 1991; Drake, 2007). A total of 12 members (six male and six female) aging between 20 to 35 years from students and academic staff of Koya university performed the sensory analysis. During this period, the samples were evaluated three times, on day 1st, 7 th and 14 th. The samples were presented to the participants in a digit code. Between each sample members should have a biscuit with drinking water for refreshing the mouth test. The result evaluated by hedonic scale process that widely used for measuring food acceptability in the 9-point scaling parameter (see Table 1). An over-all ten sensory attributes including appearance, odor, color, flavor (taste), structure, acidic taste, consistency, smell, after taste and overall acceptability analyzed.

\section{Results and discussion}

$\mathrm{pH}$ and titratable acidity are the most two important factors that deal with the food acidity. Table 2 summarized the changes in the chemical composition including $\mathrm{pH}$, titratable acidity (lactic acid percentage) and dry matter percentage of the 


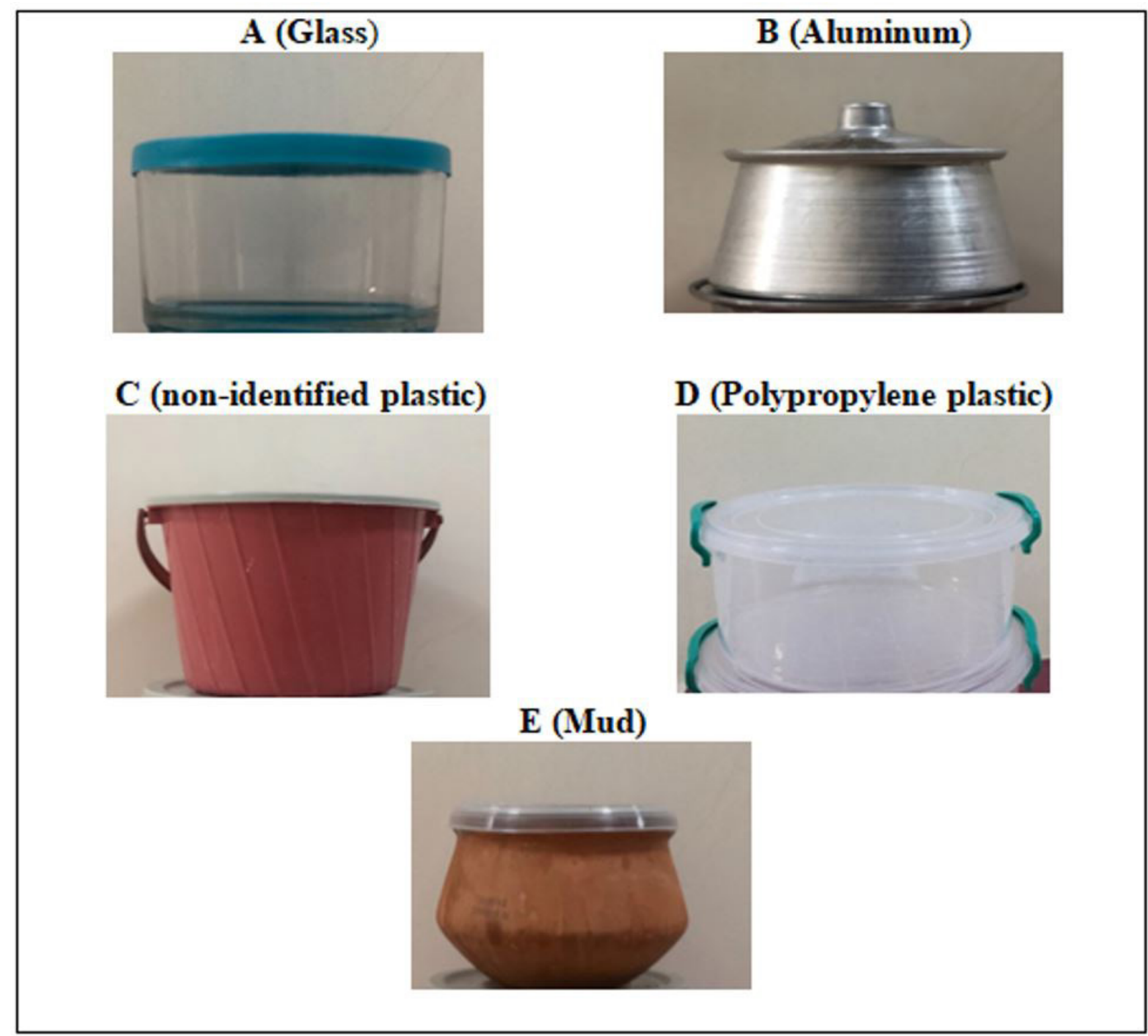

Figure 1. Characteristics of the yogurt samples container used for analysis.

Table 1. (9 point) Hedonic Scale.

\begin{tabular}{cc}
\hline & 9 point hedonic scale \\
\hline 9 & Like extremely \\
7 & like very much \\
6 & Like moderately \\
5 & Like slightly \\
4 & Neither like nor dislike \\
3 & Dislike slightly \\
2 & Dislike moderately \\
1 & Dislike very much \\
\hline
\end{tabular}

yogurt samples occurred during 14th days of storage. During this period of time, the $\mathrm{pH}$ values significantly decreased in all types of containers (Figure 2). The results revealed the highest level of $\mathrm{pH}$ recorded in both polypropylene plastic and mud containers over storage time. Also, the $\mathrm{pH}$ rang similar when the yogurt kept in glass and non-identified plastic containers. This value dropped to (4.2) in last day of session.

The percentage of lactic acid was determined by using a standard solution of sodium hydroxide in the titration process. Compare to the $\mathrm{pH}$ result, the titratable acidity gradually increased over 14 days of storage (Figure 3). Maximum acid concentration indicated in those samples that packed in both aluminum and polypropylene plastic containers at the second session and remained almost constant at last session of storage. This may be related to the over growth of lactic acid bacteria in these two yogurt samples.

The result of dry matter percentage shown in (Figure 4) and practically similar for all the cases in the first week of storage. 
Table 2. Chemical examination of yogurt during the period of storage.

\begin{tabular}{|c|c|c|c|c|c|c|}
\hline \multirow{2}{*}{ parameters } & \multirow[t]{2}{*}{ storage period } & \multicolumn{5}{|c|}{ Yogurt Sample } \\
\hline & & $\mathrm{A}$ & $\mathrm{B}$ & $\mathrm{C}$ & $\mathrm{D}$ & $\mathrm{E}$ \\
\hline \multirow[t]{3}{*}{$\mathrm{PH}$} & 1 & 4.5 & 4.5 & 4.45 & 4.55 & 4.6 \\
\hline & 7 & 4.4 & 4.4 & 4.3 & 4.45 & 4.5 \\
\hline & 14 & 4.25 & 4.3 & 4.2 & 4.35 & 4.4 \\
\hline \multirow{3}{*}{$\begin{array}{l}\text { Titratable Aciditity } \\
\text { (lactic acid \%) }\end{array}$} & 1 & $0.66 \%$ & $0.40 \%$ & $0.50 \%$ & $0.66 \%$ & $0.40 \%$ \\
\hline & 7 & $0.77 \%$ & $1.10 \%$ & $0.70 \%$ & $1.10 \%$ & $0.40 \%$ \\
\hline & 14 & $0.99 \%$ & $1.10 \%$ & $0.88 \%$ & $1.11 \%$ & $0.88 \%$ \\
\hline \multirow[t]{3}{*}{ Dry matter \% } & 1 & $82.30 \%$ & $84.60 \%$ & $83.30 \%$ & $83.30 \%$ & $82.30 \%$ \\
\hline & 7 & $83.30 \%$ & $85.60 \%$ & $88 \%$ & $86.60 \%$ & $83.30 \%$ \\
\hline & 14 & $86.60 \%$ & $86 \%$ & $98 \%$ & $93.30 \%$ & $83.40 \%$ \\
\hline
\end{tabular}

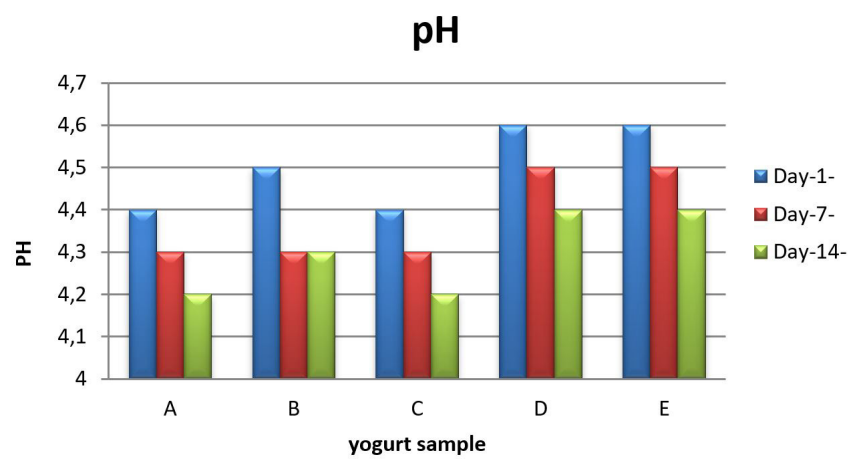

Figure 2. pH changes of yogurt during the period of storage.

\section{Titratable Acidity (lactic acid \%)}

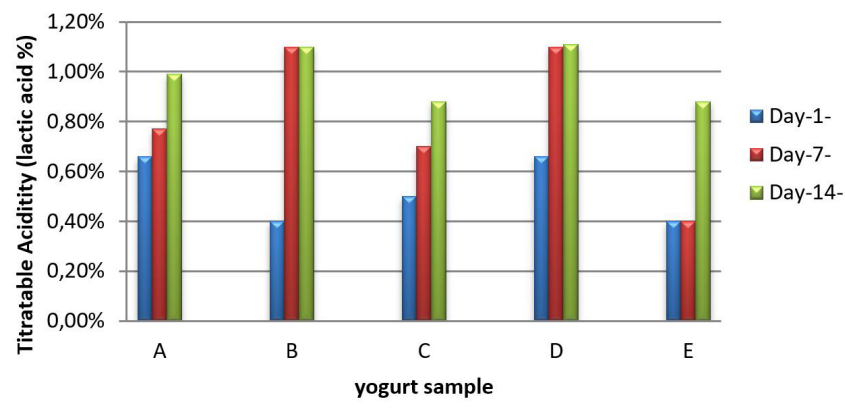

Figure 3. Titratable acidity percentage of yogurt during the period of storage.

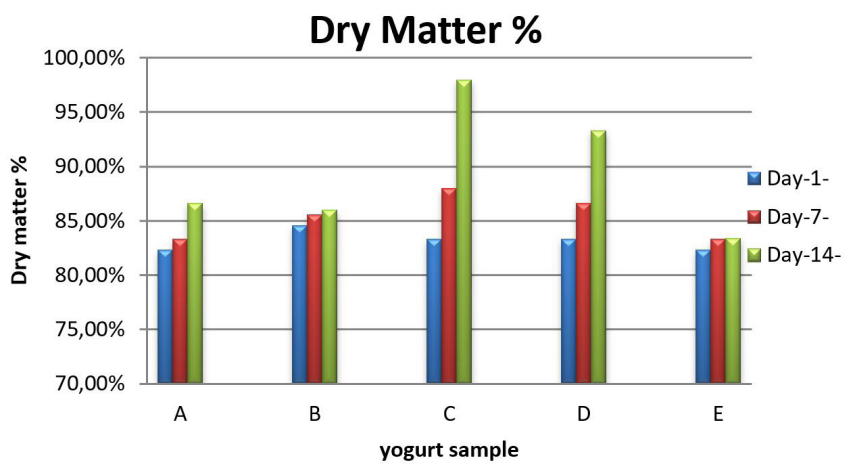

Figure 4. Dry matter percentage of yogurt during the period of storage.
From the obtained results, this percentage rapidly increased in those samples that are packed in non-identified plastic and polypropylene plastic containers. The Sample in mud container had the least percent of dry matter content due to the thickness of the material compared to others.

Results from the microbiological analysis for quality of yogurt samples packed in different packaging material during 14 days of the storage period are shown in Table 3. Studies indicates that packaging may be a potential source for dairy contamination (Carvalho et al., 2021). The total amount of lactic acid bacteria in yogurt should be ranged in 106-107 CFU and yeast $\geq 102$ CFU per $1 \mathrm{~g}$ of product (Kliks et al., 2019). In this study the number lactic acid bacteria present in sample E (Mud container) higher than other sample in the 1st day of storage. While sample B (aluminum containers) has the maximum count number and Sample $\mathrm{C}$ has the least lactic acid bacteria count in day 7 th and 14 th at 106 dilutions.

Although yogurts are usually spoiled by yeasts (Mataragas et al., 2011), in this study the result shows over 14th day of storage among all the samples, sample B (aluminum containers) presented the maximum number of fungi on the PDA, the least fungi count was seen in samples A.

Based on microbiological analysis in this study using aluminum containers for packing may affect the quality and safety of yogurt production. In addition, some studies approved that aluminum metal can leach into a food product especially when acid foods are stored in the containers. Also, they clearly indicated that contaminated milk and milk products with aluminum material may carry high health hazards to the consumers (Meshref et al., 2015).

To identify the organism's colonies morphology selected media examined under microscope and (saccharomyces boulardii) presence in sample B. (see Figure 5)

An average result of sensory characteristics for each three days of evaluation was showed on Figures 6,7 and 8. Initially, all the yogurt samples did not show any significant difference among sensory properties in the 1st day. This might be due to the use of similar process and the same source of milk. However, at the second evaluation session a major difference in appearance and consistency occurred. The results proved that in terms of appearance, color, structure and consistency sample $\mathrm{B}$ (aluminum container) scored the highest point. The scores 
Table 3. Microbiological analysis of yogurt samples during the period of storage.

\begin{tabular}{ccccc}
\hline \multirow{2}{*}{ Storage period } & \multicolumn{2}{c}{ Total viable bacteria count on NA } & \multicolumn{2}{c}{ Total fungi count on the PDA } \\
\cline { 2 - 5 } & maximum count & minimum count & maximum count & minimum count \\
\hline 1st day & sample E & sample D & sample B & sample C \\
7th day & sample B & sample C & sample B & sample E \\
14th day & sample B & sample C & sample B & sample A \\
\hline
\end{tabular}
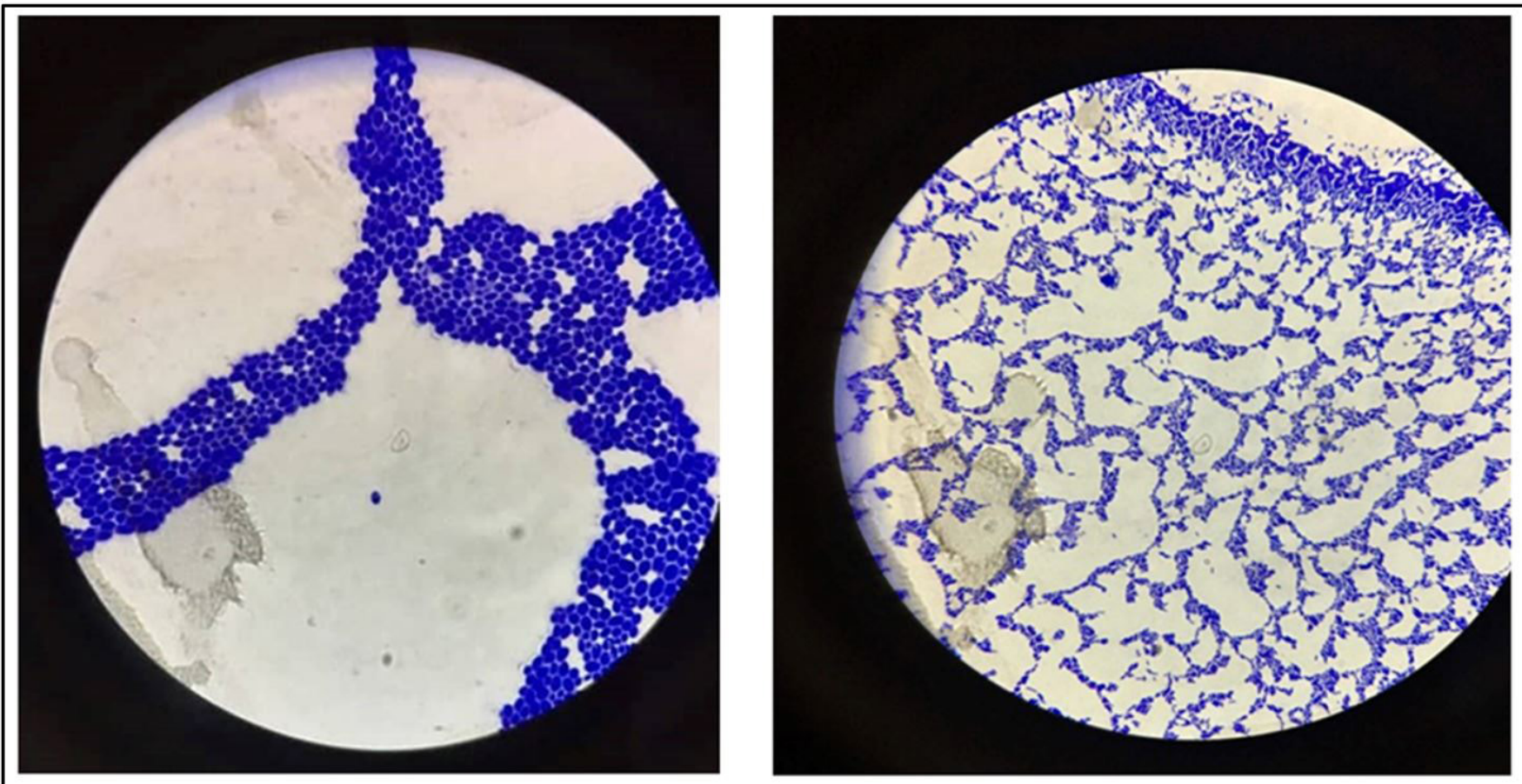

Figure 5. Microbiological analysis of yogurt samples under microscope at 14th day the of storage

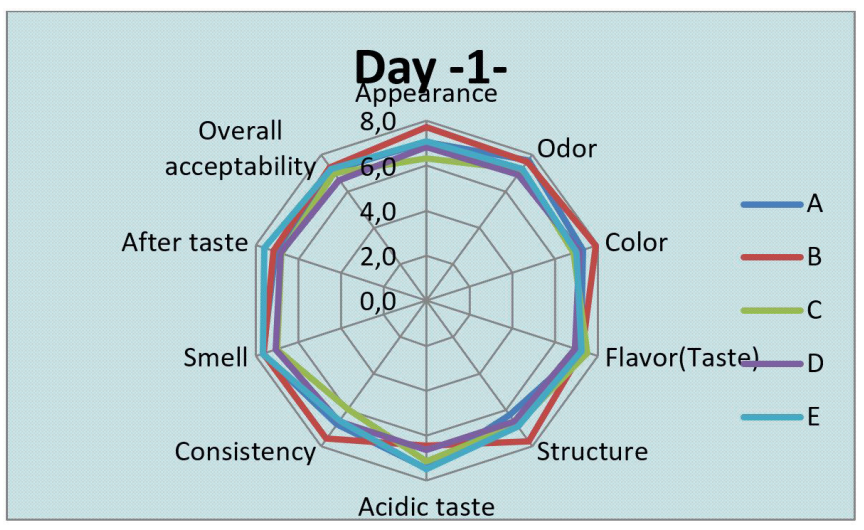

Figure 6. Sensory properties evaluation of yogurt samples in day (1).

of yogurt sample in aluminum container were slightly higher than others in most of the sensory properties in day 14th of storage. In overall acceptability the lowest score given to sample $\mathrm{D}$ (polypropylene plastic container). Despite of fewer score in some properties the participants preferred sample A (Glass) as an overall acceptability.

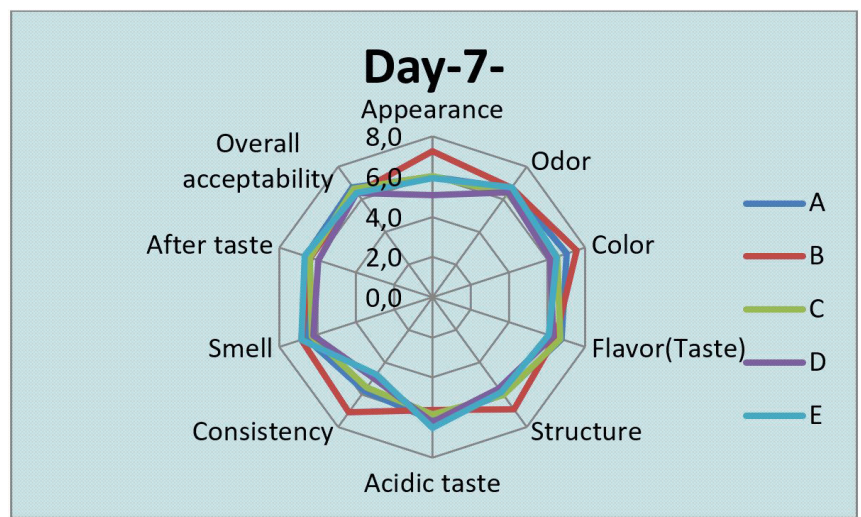

Figure 7. Sensory properties evaluation of yogurt samples in day (7).

This result suggests that the participants have a different attitude in using material for food packaging. In most of the sensory properties aluminum packaging for yogurt was preferable by the participants. According to (López et al., 2000; Meshref et al., 2015) the use of aluminum containers for preparation of milk and for fermentation of yoghurt may increase and leaching of this metal 


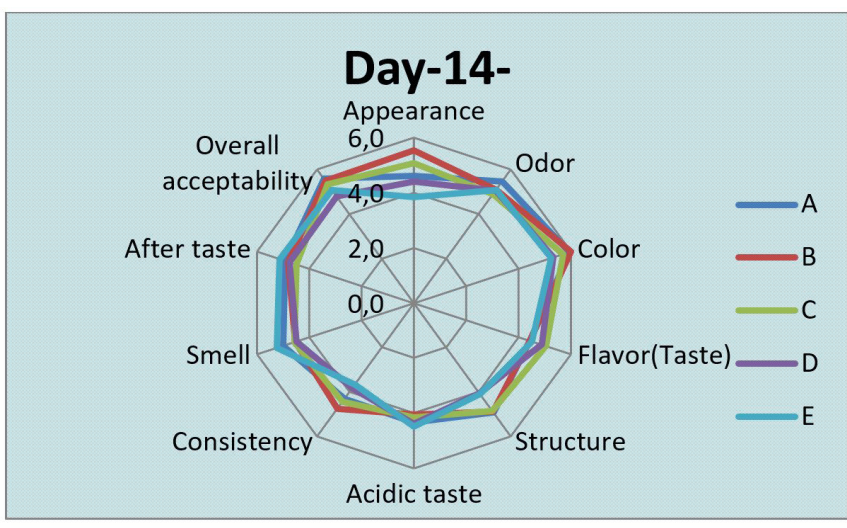

Figure 8. Sensory properties evaluation of yogurt samples in day (14).

from utensils is influenced by the quality of the containers, $\mathrm{pH}$ level, duration of cooking and preparation conditions.

\section{Conclusion}

Package material play a significant role in determining the shelf life of a food product. Therefore, selecting of an appropriate packing material maintains product quality characteristics such as physicochemical and microbiological parameters during the storage. . This study shows the influences the type of packaging on quality of homemade yogurt during a period of storage. The result observed that each type containers used as a packaging material had a great consequence on chemical, microbiological and sensory properties of product.

\section{Reference}

Alhelfi, N. A. (2016). Assessment of the efficiency of petrifim method in study of bacteriological quality of some homemade dairy products in local market of Basra. Food Science and Quality Management, $54,39-46$.

Association of Official Analytical Chemists - AOAC. (2000). Official Methods of Analysis (17th ed.). Washington, DC: AOAC.

Bradley, R. L., Arnold, E., Barbano, D. M., Semerad, R. G., Smith, D. E., \& Vines, B. K. (1992). Chemical and physical methods. In: R. T. Marshall (Ed.), Standard methods for the examination of dairy products (16th ed., pp. 433-531). Washington, DC: American Public Health Association.

Brody, A. L. (2006). Fermented dairy packaging materials. R.C. Chandan, A. Kilara, Y.H. Hui (Eds.), In: Manufacturing Yogurt and Fermented Milks. Oxford: Blackwell Publishing. http://dx.doi. org/10.1002/9780470277812.ch8.

Carvalho, L. G., Alvim, M. M. A., Fabri, R. L., \& Apolônio, A. C. M. (2021). Staphylococcus aureus biofilm formation in Minas Frescal cheese packaging. International Journal of Dairy Technology, 74(3), 575-580. http://dx.doi.org/10.1111/1471-0307.12783.

Drake, M. A. (2007). Invited review: sensory analysis of dairy foods. Journal of Dairy Science, 90(11), 4925-4937. http://dx.doi.org/10.3168/ jds.2007-0332. PMid:17954731.
El-Shafei, S. M. S., Sakr, S. S., \& Abou-Soliman, N. H. I. (2019). The impact of supplementing goats' milk with quinoa extract on some prop-erties of yoghurt. International Journal of Dairy Technology. International Journal of Dairy Technology, 73(1), 126-133. http:// dx.doi.org/10.1111/1471-0307.12628.

Germani, A., Luneia, R., Nigro, F., Vitiello, V., Donini, L. M., \& Balzo, V. (2014). The yogurt amino acid profile's variation during the shelf-life. Annali di igiene: medicina preventiva e di comunità, 26(3), 205-212. http://dx.doi.org/10.7416/ai.2014.1978. PMid:24998211.

Geueke, B., Groh, K., \& Muncke, J. (2018). Food packaging in the circular economy: overview of chemical safety aspects for commonly used materials. Journal of Cleaner Production, 193, 491-505. http:// dx.doi.org/10.1016/j.jclepro.2018.05.005.

Hadjimbei, E., Botsaris, G., Goulas, V., Alexandri, E., Gekas, V., \& Gerothanassis, I. P. (2020). Functional stability of goats' milk yoghurt supplemented with Pistacia atlantica resin extracts and Saccharomyces boulardii. International Journal of Dairy Technology, 73(1), 134-143. http://dx.doi.org/10.1111/1471-0307.12629.

Harper, S. J., Barnes, D. L., Bodyfelt, F. W., \& McDaniel, M. R. (1991). Sensory ratings of commercial plain yogurts by consumer and descriptive panels. Journal of Dairy Science, 74(9), 2927-2935. http:// dx.doi.org/10.3168/jds.S0022-0302(91)78476-2.

Kliks, J., Leśniak, A., Spruch, M., Szołdra, S., \& Czabaj, S. (2019). Quality characteristics of natural yoghurts produced with lactulose supplementation. Integr Food Nutr Metab, 6(3). http://dx.doi. org/10.15761/IFNM.1000253.

López, F. F., Cabrera, C., Lorenzo, M. L., \& López, M. C. (2000). Aluminum content in foods and beverages consumed in the spanish diet. Journal of Food Science, 65(2), 206-210. http://dx.doi. org/10.1111/j.1365-2621.2000.tb15980.x.

Marsh, K., \& Bugusu, B. (2007). Food packaging - roles, materials, and environmental issues. International Journal of Food Sciences, 72(3), R39-R55. http://dx.doi.org/10.1111/j.1750-3841.2007.00301.x. PMid:17995809.

Mataragas, M., Dimitriou, V., Skandamis, P. N., \& Drosinos, E. H. (2011). Quantifying the spoilage and shelf-life of yoghurt with fruits. Food Microbiology, 28(3), 611-616. http://dx.doi.org/10.1016/j. fm.2010.11.009. PMid:21356472.

Meshref, A. M. S., Moselhy, W. A., \& Hassan, N. E. Y. (2015). Aluminium content in milk and milk products and its leachability from dairy utensils. International Journal of Dairy Science, 10(5), 236-242. http://dx.doi.org/10.3923/ijds.2015.236.242.

Mohanty, F., \& Swain, S. K. (2017). Bionanocomposites for Food Packaging Applications. In A. E. Oprea, \& A. M. Grumezescu (Eds.), Nanotechnology applications in food (pp. 363-379). Amsterdam: Elsevier Academic Press. http://dx.doi.org/10.1016/B978-0-12811942-6.00018-2.

Pal, M., Mulu, S., Tekle, M., Pintoo, S. V., \& Prajapati, J. P. (2016). Bacterial contamination of dairy products. Beverage and Food World, 43(9), 40-44.

Pena, F. L., Souza, M. C., Valle, M. C. P. R., Bezerra, R. M. N., Rostagno, M. A., \& Antunes, A. E. C. (2021). Probiotic fermented milk with high content of polyphenols: study of viability and bioaccessibility after simulated digestion. International Journal of Dairy Technology, 74(1), 170-180. http://dx.doi.org/10.1111/1471-0307.12735.

Prescott, M. L., Harley, S. P., \& Klein, A. D. (2004). Microbiology. Dubuque: W.M.C. Brown publisher. 